\title{
A systematic review on robotic coronary artery bypass graft surgery
}

\author{
Christopher Cao ${ }^{1,2}$, Praveen Indraratna ${ }^{3,4}$, Mathew Doyle ${ }^{2}$, David H. Tian ${ }^{1,5}$, Kevin Liou ${ }^{3}$, Stine \\ Munkholm-Larsen ${ }^{1}$, Ciska Uys ${ }^{2}$, Sohaib Virk ${ }^{1}$
}

${ }^{1}$ The Collaborative Research (CORE) group, Macquarie University, Sydney, Australia; ${ }^{2}$ Department of Cardiothoracic Surgery, St. George Hospital, Sydney, Australia; ${ }^{3}$ Department of Cardiology, Prince of Wales Hospital, Sydney, Australia; ${ }^{4}$ University of New South Wales, Sydney, Australia; ${ }^{5}$ Royal North Shore Hospital, Sydney, Australia

Correspondence to: Christopher Cao, MBBS, BSc (1 $1^{\text {st }}$ Hon), PhD. Department of Cardiothoracic Surgery, St. George Hospital, Gray Street, Kogarah, New South Wales 2218, Australia. Email: drchriscao@gmail.com.

Background: Robotic-assisted coronary artery bypass graft surgery (CABG) has been performed over the past decade. Despite encouraging results from selected centres, there is a paucity of robust clinical data to establish its clinical safety and efficacy. The present systematic review aimed to identify all relevant clinical data on robotic CABG. The primary endpoint was perioperative mortality, and secondary endpoints included perioperative morbidities, anastomotic complications, and long-term survival.

Methods: Electronic searches were performed using three online databases from their dates of inception to 2016. Relevant studies fulfilling the predefined search criteria were categorized according to surgical techniques as (I) totally endoscopic coronary artery bypass without cardiopulmonary bypass (TECAB offpump); (II) TECAB on-pump; and robotic-assisted mammary artery harvesting followed by minimally invasive direct coronary artery bypass (robotic MIDCAB).

Results: The present systematic review identified 44 studies that fulfilled the study selection criteria, including nine studies in the TECAB off-pump group and 16 studies in the robotic MIDCAB group. Statistical analysis reported a pooled mortality of $1.7 \%$ for the TECAB off-pump group and $1.0 \%$ for the robotic MIDCAB group. Intraoperative details such as the number and location of grafts performed, operative times and conversion rates, as well as postoperative secondary endpoints such as morbidities, anastomotic complications and long-term outcomes were also summarized for both techniques.

Conclusions: A number of technical, logistic and cost-related issues continue to hinder the popularization of the robotic CABG procedure. Current clinical evidence is limited by a lack of randomized controlled trials, heterogeneous definition of techniques and complications, as well as a lack of robust clinical followup with routine angiography. Nonetheless, the present systematic review reported acceptable perioperative mortality rates for selected patients at specialized centres. These results should be considered as a useful benchmark for future studies, until further data is reported in the form of randomized trials.

Keywords: Robotic surgery; coronary artery bypass graft surgery (CABG); systematic review

Submitted Oct 31, 2016. Accepted for publication Nov 06, 2016.

doi: 10.21037/acs.2016.11.08

View this article at: http://dx.doi.org/10.21037/acs.2016.11.08

\section{Introduction}

Coronary artery bypass graft surgery (CABG) remains the standard of treatment for selected patients with coronary artery disease (1). Significant long-term angiographic and clinical benefits of CABG have been attributed to the left internal mammary artery (LIMA)-to-left anterior descending artery (LAD) graft, with historical studies demonstrating survival benefits over long-term followup beyond 15 -years $(2,3)$. Histopathological studies have identified particular characteristics of the LIMA endothelium, such as fewer fenestrations, lower intercellular junction permeability, greater anti-thrombotic molecules and higher nitric oxide production, all of which make 
LIMA more resistant to atherosclerosis compared to saphenous vein conduits (4). The superiority of the LIMAto-LAD graft is one of the main indications for surgical revascularization in the current era of drug-eluting stents (5).

Over the past two decades, minimally invasive surgery has evolved to influence many surgical specialties, including both cardiac and thoracic surgery (6-8). Complex cardiac operations such as mitral valve surgery and $C A B G$ have been performed with safety and efficacy through smaller incisions compared to the conventional sternotomy approach (7). Since the 1990s, robotic systems have been developed to facilitate minimally invasive cardiac surgery. Historical operating systems such as the Automated Endoscopic System for Optical Positioning (AESOP) and the Zeus Robotic Surgical System have evolved to the current da Vinci Surgical System (Intuitive Surgical, Inc., Sunnyvale, CA, USA), which was approved for use by the Food and Drug Administration (FDA) in 2000.

Despite encouraging reports from small retrospective institutional studies, there remains a paucity of robust clinical data on robotic-assisted CABG procedures. Heterogeneous classification of 'robotic CABG' techniques and nonstandardized reporting of endpoints have further hindered any meaningful analysis of the existing literature. The current systematic review aimed to assess the clinical outcomes of robotic-assisted CABG procedures according to three defined surgical techniques: totally endoscopic coronary artery bypass without cardiopulmonary bypass (TECAB off-pump); TECAB with cardiopulmonary bypass (TECAB on-pump); and robotic-assisted LIMA harvesting followed by off-pump manual anastomosis of LIMA-to-LAD through minimally invasive direct coronary artery bypass (robotic MIDCAB). The primary endpoint was perioperative mortality, and secondary endpoints included perioperative morbidities, anastomotic complications and long-term survival.

\section{Methods}

\section{Search strategy and study selection}

Electronic searches were performed using Medline, EMBASE and Central Register of Controlled Trials from their dates of inception to January 2016. The search terms ("CABG" or "coronary artery bypass") and ("robotic OR robot") were combined as both keywords and MeSH terms. This was supplemented by manually searching the reference lists of key reviews and all potentially relevant studies. Two reviewers (S.V. and P.I.) independently screened the title and abstract of records identified in the search. Full-text publications were subsequently reviewed separately if either reviewer considered the manuscript as potentially eligible for inclusion. Disagreements regarding study selection were resolved by discussion and consensus.

\section{Eligibility criteria}

Selected studies included those reporting peri-operative mortality after robotically assisted CABG procedures. These studies were categorized according to surgical techniques as (I) TECAB off-pump; (II) TECAB on-pump; (III) robotic MIDCAB. Studies that reported a mixture of surgical techniques were included for statistical analysis only when separate datasets were reported for patients in each group. All publications were limited to those involving human subjects and written in English, and studies with fewer than ten patients were excluded. When duplicated studies with accumulating numbers of patients or increased lengths of follow-up were identified, only the most complete reports were included for assessment.

\section{Surgical techniques}

Following intubation with a dual-lumen endotracheal tube, the patient was positioned supine with the left side elevated to 30 degrees and the left arm remaining at the side. With selective ventilation of the right lung and carbon dioxide insufflation of the left pleural space, three ports were inserted into the left thorax to optimize visualization of the surgical field and to maximize the range of motion for the robotic arms. Exact positioning of the ports depended on the surgeon's preference, target vessels, and patient body habitus. The robotic-assisted LIMA harvest was then performed via the two working ports under endoscopic vision through the third port. Upon completion of LIMA harvest and systemic heparinization, occluding bulldog clamps were be applied to the proximal LIMA, prior to grafting through a totally endoscopic approach, including either TECAB on-pump or TECAB off-pump, or via a left anterior mini-thoracotomy by robotic MIDCAB.

\section{On-pump TECAB}

Cardiopulmonary bypass was typically established via femoral venous and femoral or axillary arterial cannulation. Aortic occlusion could be achieved by an endovascular occluding balloon, placed and inflated in the ascending 
aorta under transesophageal ultrasound guidance. Cardioplegia could be delivered directly into the aortic root through a distal channel in the endoballoon. Alternatively, an endoscopic trans-aortic clamp could be applied via a port site in the chest wall and antegrade cardioplegia delivered via an endoscopically-placed vent needle in the proximal ascending aorta.

\section{Off-pump TECAB}

Following conduit harvest and preparation, a fourth port was inserted in the left subcostal or subxiphoid plane for the insertion of tissue stabilizing devices. The da Vinci telemanipulation system has a range of Endowrist instruments, (Intuitive Surgical Services, Sunnyvale, CA, USA) including a tissue stabilizer that could be docked to and manipulated by the robotic system. Other endoscopic tissue stabilizers include the Octopus Stabilizer, the CTS system (CardioThoracic Systems Inc., Cupertino, CA, USA), or the Elite Endoscopic Stabilizer (Genzyme Surgical Products, Fall River, MA, USA). Positioning devices such as the Starfish NS (Medtronic Inc., Minneapolis, MN, USA) could be used to manipulate and position the heart for multi-vessel anastomosis.

\section{Robotic MIDCAB}

Following the harvest of the LIMA as described above, the robotic system was undocked and $\mathrm{CO}_{2}$ insufflation ceased to allow the heart to return to its natural position. An endoscope was used to identify the intended site of anastomosis and a spinal needle could be inserted through the chest wall to identify the precise location for the minithoracotomy incision. Alternatively, the previous port sites could be extended directly. A soft tissue retractor was used to provide exposure through the interspace, and the anastomosis was performed using endoscopic tissue stabilizers and standard off-pump anastomotic techniques. To maintain a consistency of surgical techniques, only offpump robotic MIDCAB studies were included for detailed statistical analysis in the present systematic review.

\section{Statistical analysis}

Baseline characteristics and operative details were presented as raw values $(\%)$, mean \pm standard deviation or median unless otherwise indicated. Pooled values for clinical outcomes were calculated using DerSimonian-Laird random-effects model and reported with $95 \%$ confidence intervals (CI) (9). For all studies, overall survival referred to freedom from death of any cause, and was calculated from the time of surgery. All statistical analyses were performed using Comprehensive Meta-analysis v2.2 (Biostat Inc., Englewood, NJ, USA). All P values were two-sided, and values $<0.05$ were considered statistically significant.

\section{Results}

Using the predefined systematic search criteria, a total of 978 unique records were identified through the database and bibliographic searches, with one additional study identified through other sources. After exclusion of duplicated studies and 546 irrelevant articles based on abstracts and titles, 126 studies remained for full-text evaluation. Of these, 44 studies met the inclusion criteria, including nine studies in the TECAB off-pump group (10-18); two studies in the TECAB on-pump group $(19,20)$; and 16 studies in the robotic MIDCAB group (10,21-33). One study provided separate data for both the TECAB offpump and robotic MIDCAB groups, and was included for analysis in both groups (10). Eighteen additional studies reported on a mixture of different surgical techniques (18,34-53). A summary of the study selection process is presented in the PRISMA chart in Figure 1, and a summary of study characteristics is presented in Table 1 .

All of the studies were observational studies, including clinical data on a total of 8,034 patients who underwent CABG. Twenty-one studies were excluded from the final analysis due to a mixed dataset for different surgical techniques (42-53) or use of cardiopulmonary bypass (36-41), or use of an outdated robotic system other than the da Vinci system $(18,34,35)$. Of the patients who were included for statistical analysis in the selected studies on off-pump TECAB, on-pump TECAB and robotic MIDCAB, the mean age ranged from 58 to 67 , and $51-88 \%$ of patients were male. The presence of hypertension, previous myocardial infarction (MI) and diabetes mellitus were reported in $50-92 \%, 7-56 \%$ and $13-51 \%$ of patients, respectively. Preoperative estimated left ventricular ejection fraction (LVEF) ranged from $48-63 \%$ across studies. A summary of baseline patient characteristics is presented in Table 2. The reported follow-up duration ranged from the peri-operative period to eight years, and 20 studies reported routine angiographic follow-up 1-96 months postoperatively by either angiography or computed tomography coronary angiography (CTCA). 


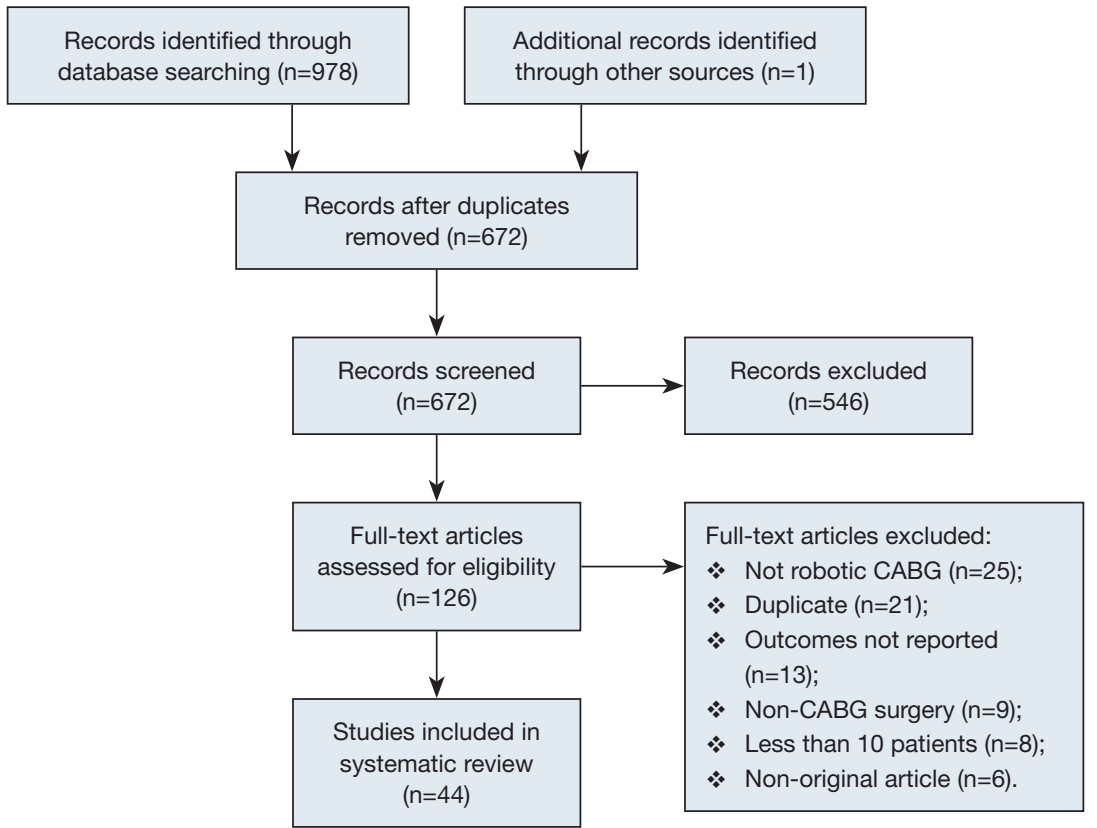

Figure 1 PRISMA chart summarizing the study selection process in the systematic review on robotic coronary artery bypass graft surgery.

Table 1 Study characteristics of relevant articles identified in the systematic review on robotic-assisted coronary artery bypass graft surgery

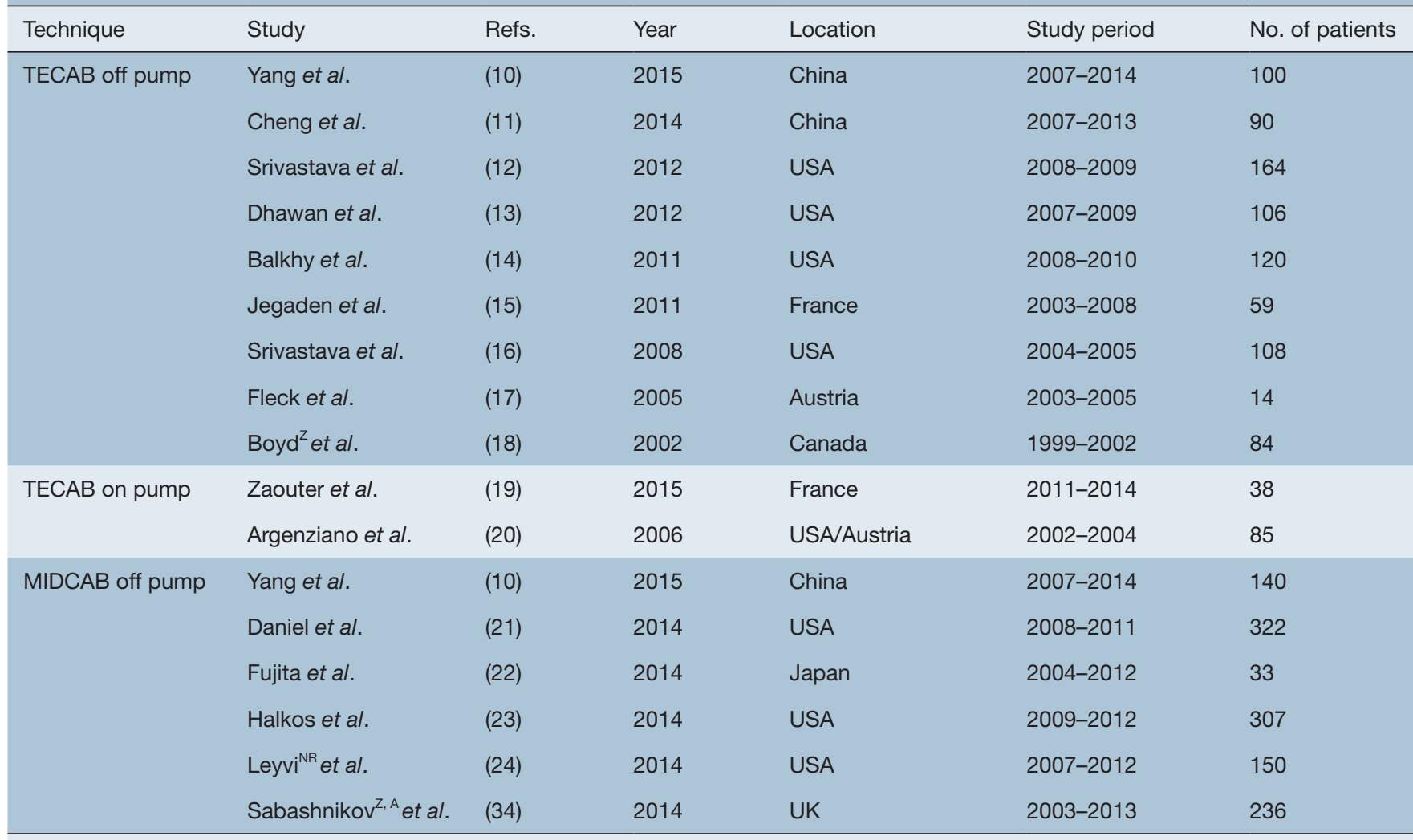

Table 1 (continued) 


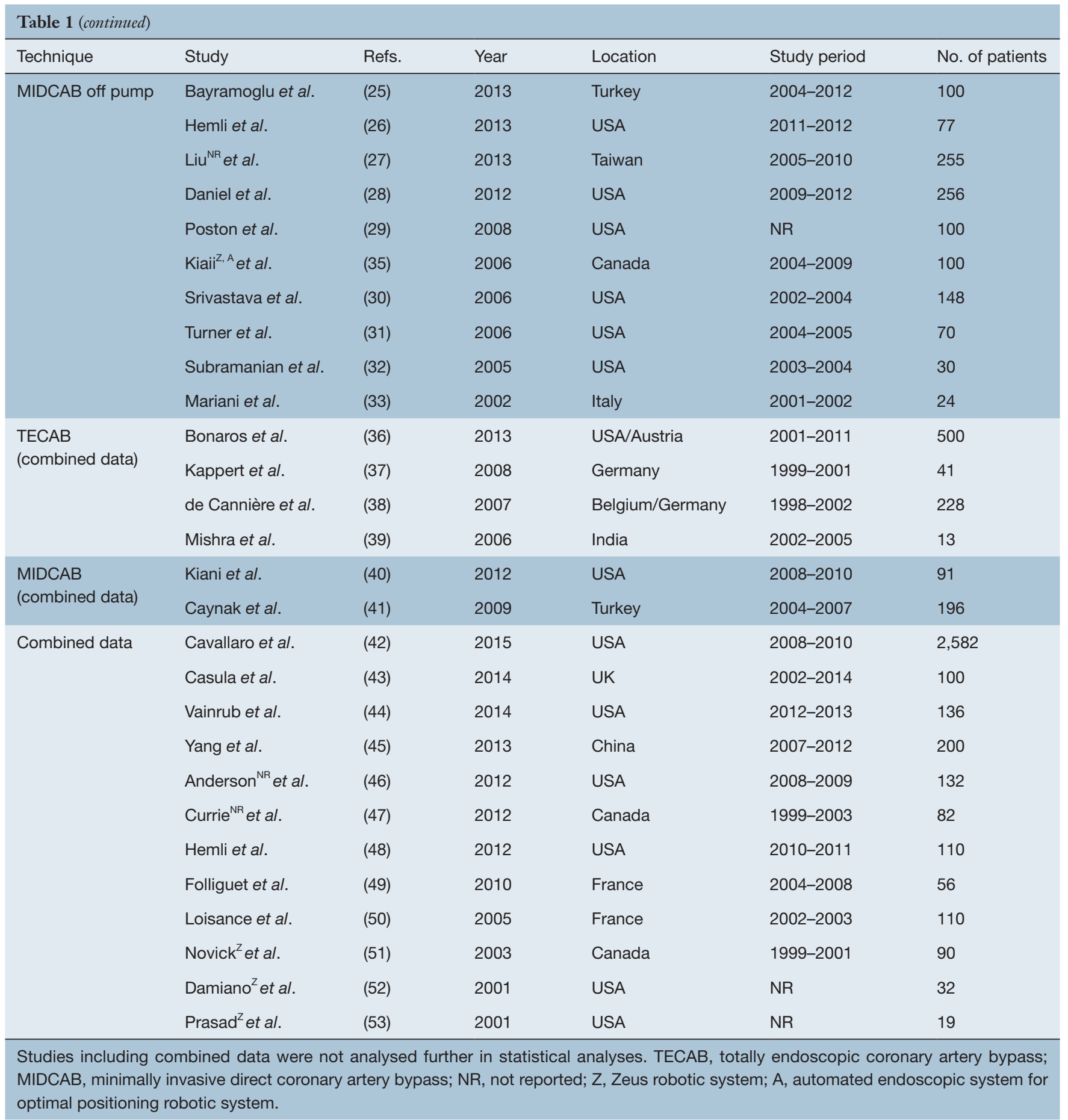

\section{Intra-operative data}

The mean number of grafts per CABG procedure ranged from 1-2.8 in all three surgical techniques. However, there was a trend of more grafts being performed in robotic
MIDCAB procedures compared to TECAB procedures. The LIMA-to-LAD graft was performed in all patients who underwent on-pump or off-pump TECAB, apart from one study. Circumflex and right coronary artery (RCA) 


\begin{tabular}{|c|c|c|c|c|c|c|c|}
\hline \multirow{7}{*}{$\begin{array}{l}\text { TECAB off } \\
\text { pump }\end{array}$} & Yang et al. (10) & $58.7 \pm 8.6$ & 84 & 50 & 20 & 26 & $62.8 \pm 5.1$ \\
\hline & Cheng et al. (11) & $59.1 \pm 10.2$ & 78 & 53 & 14 & 26 & $62.9 \pm 6.7$ \\
\hline & Srivastava et al. (12) & $62.7 \pm 10.5$ & 78 & 55 & 16 & 18 & 55 \\
\hline & Balkhy et al. (14) & $66.3 \pm 10.4$ & 72 & 61 & 7 & 19 & NR \\
\hline & Jegaden et al. (15) & $59 \pm 12$ & 94 & NR & 18 & NR & $59 \pm 8$ \\
\hline & Srivastava et al. (16) & $67.4 \pm 12.3$ & 51 & 78 & 28 & 41 & NR \\
\hline & Fleck et al. (17) & $62 \pm 5$ & 83 & NR & NR & 21 & 62 \\
\hline \multirow{9}{*}{$\begin{array}{l}\text { MIDCAB off } \\
\text { pump }\end{array}$} & Yang et al. (10) & $59.3 \pm 9.7$ & 74 & 52 & 24 & 24 & $63 \pm 5.7$ \\
\hline & Daniel et al. (21) & $62.8 \pm 12.0$ & 68 & 90 & 48 & 36 & $55.4 \pm 9.3$ \\
\hline & Fujita et al. (22) & $64 \pm 10$ & 82 & 73 & 36 & 30 & NR \\
\hline & Halkos et al. (23) & 59.1 & 71 & NR & NR & NR & 49 \\
\hline & Leyvi et al. (24) & $64.8 \pm 12.5$ & 69 & NR & 39 & 51 & $54.2 \pm 10.6$ \\
\hline & Bayramoglu et al. (25) & $59.7 \pm 9.7$ & 76 & 50 & NR & 24 & $61.8 \pm 6.6$ \\
\hline & Hemli et al. (26) & 64.5 & 65 & NR & NR & 38 & $53.4 \pm 11.0$ \\
\hline & Liu et al. (27) & $64 \pm 11$ & 81 & 79 & NR & 46 & $52 \pm 13$ \\
\hline & Mariani et al. (33) & $66 \pm 9$ & 88 & 63 & 8 & 16 & $51 \pm 8$ \\
\hline
\end{tabular}

TECAB, totally endoscopic coronary artery bypass; MIDCAB, minimally invasive direct coronary artery bypass; NR, not reported; HTN, hypertension; MI, myocardial infarction; LVEF, left ventricular ejection fraction.

grafts were performed in selected patients in two offpump TECAB studies and six off-pump MIDCAB studies. Robotic-assisted LIMA harvest duration ranged from 26 to 60 minutes. The anastomosis time for the TECAB offpump and TECAB on-pump groups ranged from 9.6-12.6 and 28-60 minutes, respectively. The mean overall operative time for the off-pump TECAB and off-pump MIDCAB groups ranged from 161-326, and 166-444 minutes, respectively. Pooled conversion rates from the intended incision were $7.0 \%$ (95\% CI, 2.8-16.9\%), 8.9\% (95\% CI, $1.3-42.7 \%$ ) and $4.4 \%$ (95\% CI, 2.9-6.6\%) in the off-pump
TECAB, on-pump TECAB, and robotic MIDCAB groups, respectively. A summary of these intraoperative outcomes is presented in Table 3.

\section{Peri-operative outcomes}

\section{Off-pump TECAB}

The pooled peri-operative mortality following off-pump TECAB was $1.7 \%$ (95\% CI, $0.9-3.2 \%)$. The rates of perioperative MI, stroke and acute kidney injury (AKI) were $1.1 \%$ (95\% CI, $0.5-2.6 \%$ ), $1.1 \%$ (95\% CI, $0.4-2.7 \%$ ) and 


\begin{tabular}{|c|c|c|c|c|c|c|c|c|c|c|}
\hline \multirow{3}{*}{$\begin{array}{l}\text { Surgical } \\
\text { technique }\end{array}$} & \multirow{3}{*}{ Study } & \multicolumn{5}{|c|}{ Grafts } & \multicolumn{3}{|c|}{ Operative time (mins) } & \multirow{3}{*}{ Conversions } \\
\hline & & \multirow{2}{*}{$\begin{array}{l}\text { Mean } \\
\text { No. }\end{array}$} & \multicolumn{2}{|c|}{ LAD } & \multirow{2}{*}{ LCx } & \multirow{2}{*}{ RCA } & \multirow{2}{*}{ Total } & \multirow{2}{*}{$\begin{array}{l}\text { LIMA } \\
\text { harvest }\end{array}$} & \multirow{2}{*}{ Anastomosis } & \\
\hline & & & $\mathrm{N}$ & $\%$ & & & & & & \\
\hline \multirow{5}{*}{$\begin{array}{l}\text { TECAB } \\
\text { off pump }\end{array}$} & Yang et al. (10) & 1 & $100 / 100$ & 100 & $0 / 100$ & $0 / 100$ & $219 \pm 58$ & NR & NR & NR \\
\hline & Srivastava et al. (12) & 1.5 & NR & - & NR & NR & 255 & 34 & 12.6 & $0 / 164$ \\
\hline & Dhawan et al. (13) & 1.8 & NR & - & NR & NR & $326 \pm 139$ & NR & NR & $11 / 106$ \\
\hline & Balkhy et al. (14) & 1.4 & $120 / 120$ & 100 & $28 / 120$ & $2 / 120$ & NR & NR & NR & $3 / 120$ \\
\hline & Jegaden et al. (15) & NR & $59 / 59$ & 100 & 0 & 0 & $204 \pm 42$ & NR & NR & $19 / 78$ \\
\hline \multirow{2}{*}{$\begin{array}{l}\text { TECAB } \\
\text { on pump }\end{array}$} & Zaouter et al. (19) & 1 & $38 / 38$ & 100 & $0 / 38$ & $0 / 38$ & NR & NR & $60 \pm 37$ & $1 / 38$ \\
\hline & Argenziano et al. (20) & 1 & $85 / 85$ & 100 & $0 / 85$ & $0 / 85$ & $353 \pm 89$ & $60 \pm 24$ & $28 \pm 11$ & $18 / 98$ \\
\hline \multirow{9}{*}{$\begin{array}{l}\text { MIDCAB } \\
\text { off pump }\end{array}$} & Yang et al. (10) & 1.0 & $139 / 140$ & 99 & $0 / 140$ & $2 / 140$ & $264 \pm 70$ & NR & NR & NR \\
\hline & Daniel et al. (21) & NR & NR & - & NR & NR & NR & NR & NR & NR \\
\hline & Fujita et al. (22) & 1 & $33 / 33$ & 100 & $0 / 33$ & $0 / 33$ & NR & NR & NR & $3 / 36$ \\
\hline & Halkos et al. (23) & 1 & $307 / 307$ & 100 & $0 / 307$ & $0 / 307$ & NR & NR & NR & $16 / 307$ \\
\hline & Leyvi et al. (24) & 1 & $150 / 150$ & 100 & $0 / 150$ & $0 / 150$ & $222 \pm 66$ & NR & NR & $1 / 150$ \\
\hline & Bayramoglu et al. (25) & NR & NR & - & NR & NR & $166 \pm 20$ & $42 \pm 6$ & NR & NR \\
\hline & Turner et al. (31) & 2.2 & $99 / 155$ & 64 & $31 / 155$ & $21 / 155$ & 284 & NR & NR & $3 / 70$ \\
\hline & Subramanian et al. (32) & 2.2 & $30 / 30$ & 100 & $20 / 30$ & $16 / 30$ & $444 \pm 49$ & NR & NR & NR \\
\hline & Mariani et al. (33) & 1.8 & $23 / 24$ & 97 & $20 / 24$ & $0 / 24$ & NR & NR & NR & NR \\
\hline
\end{tabular}

TECAB, totally endoscopic coronary artery bypass; MIDCAB, minimally invasive direct coronary artery bypass; NR, not reported; LAD, left anterior descending; LCx, left circumflex; RCA, right coronary artery; LIMA, left internal mammary artery.

$3.4 \%$ (95\% CI, 1.2-9.7\%), respectively. Re-operation for bleeding was required in $3.2 \%$ (95\% CI, 1.6-6.3\%) and peri-operative atrial fibrillation was reported in $11.7 \%(95 \%$ CI, $8.0-16.8 \%$ ). Pooled post-operative ventilation time was 8.7 hours (95\% CI, 1.5-15.9), and the pooled length of hospital and intensive care unit (ICU) stay was 5.6 days (95\% CI, 3.5-7.7) and 32.0 hours (95\% CI, 14.6-49.4), respectively.

\section{Robotic MIDCAB}

The pooled peri-operative mortality following robotic MIDCAB was $1.0 \%$ (95\% CI, $0.6-1.6 \%$ ). The rates of peri-operative MI, stroke and AKI were $1.2 \%$ (95\% CI, $0.7-2.1 \%), 0.7 \%$ (95\% CI, $0.3-1.5 \%$ ) and $1.8 \%$ (95\% CI, $1.1-2.9 \%)$, respectively. Re-operation for bleeding was required in $2.7 \%$ (95\% CI, $1.9-3.8 \%$ ), peri-operative atrial fibrillation was reported in $12.5 \%$ (95\% CI, 9.2-16.8\%) 


\begin{tabular}{|c|c|c|c|c|c|c|c|}
\hline Technique & Study & $\begin{array}{l}\text { 30-day } \\
\text { mortality (\%) }\end{array}$ & $\begin{array}{l}\text { Ventilation } \\
\text { time }(\mathrm{h})\end{array}$ & $\begin{array}{l}\text { ICU time } \\
\text { (h) }\end{array}$ & $\begin{array}{l}\text { Mean } \\
\text { LOS (d) }\end{array}$ & $\begin{array}{l}\text { Mortality beyond } \\
30 \text { days }(\%)\end{array}$ & $\begin{array}{l}\text { Follow-up } \\
\text { period }\end{array}$ \\
\hline \multirow{6}{*}{$\begin{array}{l}\text { TECAB } \\
\text { off pump }\end{array}$} & Yang et al. (10) & $0 / 100(0)$ & $13.9 \pm 4.0$ & $40.8 \pm 21.1$ & NR & NR & NR \\
\hline & Cheng et al. (11) & $0 / 90(0)$ & 6.77 & 26.3 & NR & NR & NR \\
\hline & Dhawan et al. (13) & 4/106 (3.8) & NR & NR & NR & NR & NR \\
\hline & Balkhy et al. (14) & $1 / 120(0.8)$ & NR & NR & $3.3 \pm 2.4$ & $1 / 120(0.8)$ & $6-12$ months \\
\hline & Jegaden et al. (15) & $1 / 59(1.7)$ & $4.6 \pm 2.4$ & $23.0 \pm 19.2$ & $5.5 \pm 1.6$ & $2 / 59(3.4)$ & 3 years \\
\hline & Srivastava et al. (16) & $0 / 93(0)$ & NR & NR & NR & NR & NR \\
\hline $\begin{array}{l}\text { TECAB } \\
\text { on pump }\end{array}$ & Argenziano et al. (20) & 0/85 (0) & $14 \pm 28$ & $35 \pm 37$ & $5.1 \pm 3.4$ & 0/85 (0) & 3 months \\
\hline \multirow{9}{*}{$\begin{array}{l}\text { MIDCAB } \\
\text { off pump }\end{array}$} & Yang et al. (10) & $0 / 140(0)$ & $15.2 \pm 4.5$ & $50.4 \pm 50.4$ & NR & NR & NR \\
\hline & Daniel et al. (21) & $1 / 322(0.3)$ & 19.0 & 42.7 & 4.8 & $1 / 100(1.0)$ & 3.5 years \\
\hline & Fujita et al. (22) & $0 / 33(0)$ & NR & NR & NR & NR & NR \\
\hline & Halkos et al. (23) & 4/307 (1.3) & 2 & 24 & 4 & NR & NR \\
\hline & Leyvi et al. (24) & $0 / 150(0)$ & NR & NR & 6 & NR & NR \\
\hline & Bayramoglu et al. (25) & $0 / 100(0)$ & $5.8 \pm 3$ & $14.4 \pm 2.6$ & $5.5 \pm 1.7$ & $4 / 100(4.0)$ & 8 years \\
\hline & Turner et al. (31) & $0 / 70(0)$ & $4.6 \pm 1.5$ & NR & 4.5 & NR & NR \\
\hline & Subramanian et al. (32) & $0 / 30(0)$ & NR & NR & NR & NR & NR \\
\hline & Mariani et al. (33) & $0 / 24(0)$ & $7 \pm 2$ & $13 \pm 8$ & $3.4 \pm 2.0$ & NR & NR \\
\hline
\end{tabular}

TECAB, totally endoscopic coronary artery bypass; MIDCAB, minimally invasive direct coronary artery bypass; NR, not reported; ICU, intensive care unit; LOS, length of stay.

and wound infection occurred in $1.9 \%$ (95\% CI, 1.2-3.1\%). Pooled post-operative ventilation time was 8.7 hours (95\% CI, 5.6-11.8), and the pooled length of hospital and ICU stay was 4.7 days (95\% CI, 3.7-5.7) and 26.7 hours (95\% CI, 19.9-33.4), respectively. A summary of these perioperative outcomes is presented in Tables 4,5 and 6 . There was insufficient data to statistically summarize clinical outcomes following on-pump TECAB from the limited number of studies.

\section{Anastomotic complications and long-term outcomes}

Anastomotic complications were reported using heterogeneous endpoints, such as graft occlusion, graft failure and graft stenosis. Postoperative routine imaging of coronary grafts by angiography or CTCA was performed in 12 out of 25 studies. In the remaining studies, graft complications were detected by investigation of symptomatic patients. The reported rates of graft occlusion ranged from 0-6.7\%, 


\begin{tabular}{|c|c|c|c|c|c|c|c|c|}
\hline \multirow{6}{*}{$\begin{array}{l}\text { TECAB } \\
\text { off pump }\end{array}$} & Yang et al. (10) & $0 / 100(0)$ & $2 / 100(2.0)$ & NR & $1 / 100(1)$ & NR & NR & $0 / 100(0)$ \\
\hline & Cheng et al. (11) & $0 / 90(0)$ & NR & NR & NR & NR & NR & NR \\
\hline & Dhawan et al. (13) & NR & NR & 17/106 (16) & NR & NR & NR & NR \\
\hline & Balkhy et al. (14) & $1 / 120(0.8)$ & NR & NR & $2 / 120(1.7)$ & NR & $0 / 120(0)$ & $1 / 120(0.8)$ \\
\hline & Jegaden et al. (15) & 2/59 (3.4) & $4 / 59(6.8)$ & NR & $5 / 59(8.5)$ & NR & NR & $0 / 59(0)$ \\
\hline & Srivastava et al. (16) & 0/93 (0) & $1 / 93(1.1)$ & $12 / 93(13.0)$ & NR & $1 / 93(1.1)$ & NR & $0 / 93(0)$ \\
\hline $\begin{array}{l}\text { TECAB } \\
\text { on pump }\end{array}$ & Argenziano et al. (20) & $1 / 85(1.2)$ & $4 / 85(4.7)$ & $1 / 85(1.2)$ & $3 / 85(3.5)$ & $1 / 85(1.2)$ & $5 / 85(5.9)$ & NR \\
\hline \multirow{9}{*}{$\begin{array}{l}\text { MIDCAB } \\
\text { off pump }\end{array}$} & Yang et al. (10) & $0 / 140(0)$ & $1 / 140(0.7)$ & NR & $0 / 140(0)$ & NR & $4 / 140(2.9)$ & $0 / 140(0)$ \\
\hline & Daniel et al. (21) & NR & NR & NR & 9/322 (2.8) & NR & NR & NR \\
\hline & Fujita et al. (22) & $0 / 33(0)$ & NR & NR & NR & NR & NR & $0 / 33(0)$ \\
\hline & Halkos et al. (23) & $5 / 307(1.6)$ & NR & 47/307 (15.0) & $7 / 307(2.3)$ & $6 / 307(2.0)$ & 6/307 (2.0) & $1 / 307(0.3)$ \\
\hline & Leyvi et al. (24) & NR & NR & $19 / 150(13.0)$ & $2 / 150(1.3)$ & $0 / 150(0)$ & $0 / 150(0)$ & $2 / 150(1.3)$ \\
\hline & Bayramoglu et al. (25) & $0 / 100$ & NR & $0 / 100(0)$ & NR & $0 / 100(0)$ & $0 / 100(0)$ & NR \\
\hline & Turner et al. (31) & $1 / 70(1.4)$ & NR & 6/70 (8.6) & $2 / 70(2.9)$ & $0 / 70(0)$ & $2 / 70(2.9)$ & $0 / 70(0)$ \\
\hline & Subramanian et al. (32) & NR & NR & NR & $2 / 30(6.7)$ & NR & $1 / 30(3.3)$ & NR \\
\hline & Mariani et al. (33) & $1 / 24(4.1)$ & NR & NR & $1 / 24(4.2)$ & NR & NR & NR \\
\hline
\end{tabular}

TECAB, totally endoscopic coronary artery bypass; MIDCAB, minimally invasive direct coronary artery bypass; NR, not reported; MI, myocardial infarction; $A F$, atrial fibrillation; $A K I$, acute kidney injury.

and the rates of graft or anastomotic stenosis ranged from $0.7-13 \%$. Due to the variable timing of follow-up imaging and definitions of anastomotic complications, formal statistical analysis of this endpoint could not be performed. A summary of the reported data on graft complications is presented in Table 7. Mortality beyond 30 days was reported at variable time frames ranging from three months to eight years, ranging from $0-5.4 \%$. Due to the lack of standardized time intervals, detailed statistical analysis could not be performed. Reported outcomes for long-term mortality are summarized in Table 4.

\section{Discussion}

The ultimate goal of robotic CABG is to perform safe and effective coronary anastomoses through a minimally invasive approach to enhance recovery and minimize trauma. To achieve this goal, a number of techniques 


\begin{tabular}{|c|c|}
\hline Perioperative outcome & $\begin{array}{l}\% \text { incidence } \\
\text { (95\% confidence interval) }\end{array}$ \\
\hline \multicolumn{2}{|l|}{ TECAB off-pump } \\
\hline Mortality & $1.7 \%(0.9-3.2 \%)$ \\
\hline MI & $1.1 \%(0.5-2.6 \%)$ \\
\hline Stroke & $1.1 \%(0.4-2.7 \%)$ \\
\hline Acute kidney injury & $3.4 \%(1.2-9.7 \%)$ \\
\hline Reop bleeding & $3.2 \%(1.6-6.3 \%)$ \\
\hline Atrial fibrillation & $11.7 \%(8.0-16.8 \%)$ \\
\hline Ventilation time (hours) & $8.7(1.5-15.9)$ \\
\hline Hospital stay (days) & $5.6(3.5-7.7)$ \\
\hline ICU stay (hours) & $32.0(14.6-49.4)$ \\
\hline \multicolumn{2}{|l|}{ MIDCAB off-pump } \\
\hline Mortality & $1.0 \%(0.6-1.6 \%)$ \\
\hline MI & $1.2 \%(0.7-2.1 \%)$ \\
\hline Stroke & $0.7 \%(0.3-1.5 \%)$ \\
\hline Acute kidney injury & $1.8 \%(1.1-2.9 \%)$ \\
\hline Reop bleeding & $2.7 \%(1.9-3.8 \%)$ \\
\hline Atrial fibrillation & $12.5 \%(9.2-16.8 \%)$ \\
\hline Wound infect & $1.9 \%(1.2-3.1 \%)$ \\
\hline Ventilation time (hours) & $8.7(5.6-11.8)$ \\
\hline Hospital stay (days) & $4.7(3.7-5.7)$ \\
\hline ICU stay (hours) & 26.7 (19.9-33.4) \\
\hline
\end{tabular}

and robotic systems have been developed over the past 15 years, culminating in a totally endoscopic approach using the da Vinci operating system, without the need for cardiopulmonary bypass, also known as the off-pump TECAB technique. Although LIMA was commonly grafted onto the LAD as a single TECAB graft, robotic harvesting of bilateral mammary arteries was feasible and all territories of the heart could be grafted robotically (14). From a historical perspective, the AESOP system was initially developed as a voice-activated robot used to hold an endoscope, and approved by FDA for minimally invasive surgery in 1994. This was followed by the Zeus Robotic
Surgical System (Computer Motion Inc., Goleta, CA, USA), which consisted of two robotic arms mounted to the patient bed, controlled via a satellite control unit. The Zeus system was discontinued from clinical use in 2003, following the introduction of the da Vinci system, which consisted of three principle components: (I) a surgical console; (II) a computer controlled system; and (III) robotic manipulations. The surgeon was positioned at the console to grasp specially designed instrument handles. The surgeon's motions were then relayed to a computer processor, which digitized the surgeon's hand motions. The digitized information from the computer control system was then relayed in real time to robotic manipulators, which were attached to the operating room table. These manipulators held the endoscopic instrument tips, which were inserted through small ports, performing all aspects of the CABG procedure without sternotomy or thoracotomy (31).

Current limitations to the robotic CABG technique include its cost, heterogeneous clinical outcomes, limited training opportunities and evolving instrumentation for the endoscopic technique. From a technical perspective, one of the greatest challenges to robotic-assisted CABG is the anastomosis of the LIMA-to-LAD graft. To perform this critical step, the distal end of the LIMA is skeletonized prior to anastomosis, and the target coronary artery is identified and positioned. If TECAB is performed offpump, silastic bands or saddle loops can be placed either side of the anastomotic site for vessel occlusion prior to arteriotomy. Some authors advocated the use of ischemic preconditioning (14) or intra-coronary shunt placement $(18,26)$. The target vessel can be opened using an endoscopic knife and the arteriotomy performed with endoscopic Potts scissors. The distal anastomosis can be performed using robotic endoscopic sutures, U-clips (Medtronic, Minneapolis, MN, USA), or anastomotic devices such as the C-Port Flex A (Cardica, Redwood City, CA, USA). Distal anastomotic patency can be checked intraoperatively via angiography or ultrasonography $(11,14)$, or postoperatively using CTCA (17), Doppler ultrasonography (18) or formal angiography. Overall, it has been acknowledged that robust clinical outcomes, as well as improved instrumentation at affordable costs will be critical to the future development of the TECAB technique.

The present systematic review found that the majority of studies on robotic-assisted CABG procedures involved patients who underwent off-pump TECAB or roboticassisted MIDCAB techniques. This was not an unexpected finding, as the use of cardiopulmonary bypass was 


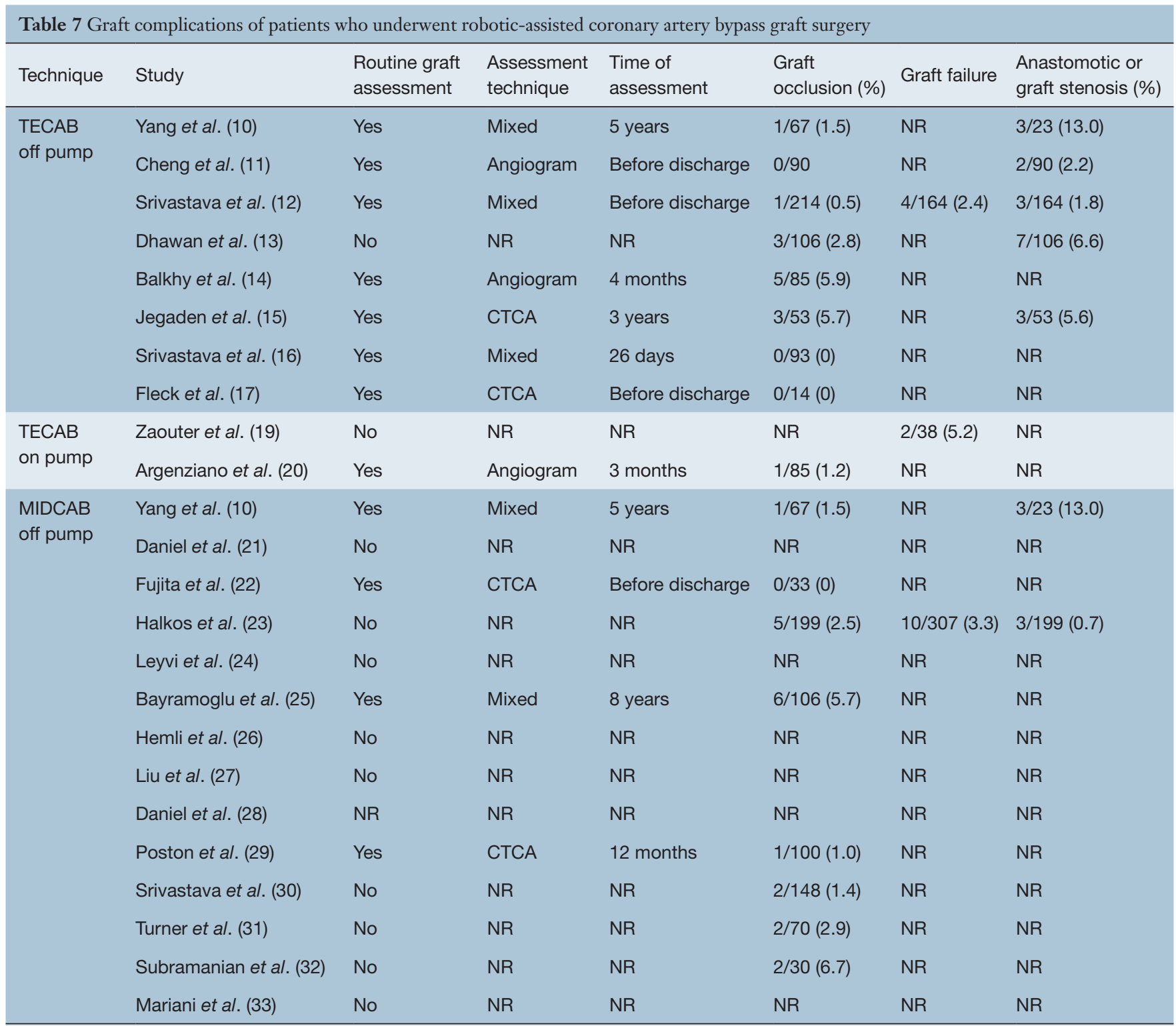

TECAB, totally endoscopic coronary artery bypass; MIDCAB, minimally invasive direct coronary artery bypass; NR, not reported; CTCA, computed tomography coronary angiogram.

acknowledged as a 'stepping stone' to off-pump TECAB for surgeons who were overcoming their technical learning curves (20). Although cardiopulmonary bypass and cardioplegia allowed the surgeon to operate on an arrested heart, the addition of peripheral cannulation and aortic clamping prolonged the operative duration, and added complications such as groin wound infections and vascular injuries (20). The patients included in the selected studies in the present systematic review were relatively young, with a mean age in the $60 \mathrm{~s}$, and well-preserved preoperative left ventricular function, with a mean ejection fraction of $>55 \%$ in the majority of studies. In addition, the numbers of anastomoses were relatively few, especially for the TECAB groups, which averaged less than two grafts in all of the studies, and almost exclusively for the LIMAto-LAD graft. Keeping these considerations in mind, results of the present systematic review demonstrated relatively safe perioperative outcomes for both the offpump TECAB and robotic MIDCAB groups, with a pooled perioperative mortality rate of $1.7 \%$ and $1.0 \%$, 
respectively. Dhawan and colleagues reported a relatively high perioperative mortality rate of $3.8 \%$ from a cohort of 106 patients, with four deaths within the perioperative period related to cardiogenic shock, fibrillatory arrest or bleeding (13). Other perioperative outcomes, such as MI, stroke, AKI, re-operation for bleeding and atrial fibrillation were comparable to contemporary data for conventional CABG procedures $(54,55)$. Other key findings of the study included anastomotic complication rates that ranged from $0.7-13 \%$. However, routine follow-up varied in relation to angiographic assessment technique, timing, and definition of endpoints. Long-term survival was also difficult to assess due to limited and non-systematic follow-up of patient cohorts, but the available data reported favorable outcomes, including one report of $4 \%$ mortality at 8 -year follow-up.

Some of the unexpected results can be rationalized with detailed examination of the surgical technique performed. For example, Zaouter et al. reported a relatively long anastomosis time of 60 minutes (19). However, this duration was measured from the time of LIMA occlusion, and included the period of time spent on target vessel identification and preparation prior to anastomosis. Similarly, although Srivastava, Poston and Subramanian reported mean total operative times of 311, 348 and 444 minutes, respectively, they also averaged 1.9-2.2 grafts, accounting for the increased operative time spent on conduit harvesting and performing the additional anastomoses $(29,30,32)$. In addition, studies of on-pump TECAB, such as the multiinstitutional study by Argenziano and colleagues, reported longer operative times due to the need for peripheral cannulation and use of a cardiopulmonary circuit (20). Finally, perioperative outcomes such as ventilation time, ICU stay, and total hospitalization time were dependent on clinical pathways specific to each institution, and prolonged times may have been multi-factorial (10).

A number of important limitations to the present systematic review should be acknowledged, and reported outcomes should be interpreted with caution. Firstly, only non-randomized, observational studies were identified, and robust comparisons with conventional CABG through the sternotomy approach were not possible using directly comparative data. Secondly, it should be noted that the patient cohort included in the present systematic review were a highly selected subgroup, with relatively favorable baseline patient characteristics, and should not be generalized to all patients with coronary artery disease, especially those who present with acute coronary syndrome. Thirdly, surgical techniques evolved over time, partly due to the learning curve of individual surgeons and institutions, and also partly due to the evolution of instrumentation available in clinical practice. Variations in surgical techniques and experience may have accounted for some of the differences between the selected observational studies.

\section{Conclusions}

Overall, the present systematic review examined the current evidence for robotic-assisted $\mathrm{CABG}$ procedures, which were mostly focused on the off-pump TECAB and off-pump MIDCAB techniques. Statistical analysis demonstrated relatively safe outcomes using perioperative mortality as the primary endpoint. However, there remains a paucity of robust clinical data related to anastomotic complications, and future studies should follow standardized, routine angiographic follow-up at predefined time intervals to demonstrate technical efficacy. Results of the present systematic review should be considered as a useful benchmark for future studies on robotic CABG, until further data is reported from randomized studies.

\section{Acknowledgements}

None.

\section{Footnote}

Conflicts of Interest: The authors have no conflicts of interest to declare.

\section{References}

1. Cao C, Manganas C, Bannon P, et al. Drug-eluting stents versus coronary artery bypass graft surgery in left main coronary artery disease: a meta-analysis of early outcomes from randomized and nonrandomized studies. J Thorac Cardiovasc Surg 2013;145:738-47.

2. Cameron A, Davis KB, Green G, et al. Coronary bypass surgery with internal-thoracic-artery grafts-effects on survival over a 15 -year period. $\mathrm{N}$ Engl J Med 1996;334:216-9.

3. Loop FD, Lytle BW, Cosgrove DM, et al. Influence of the internal-mammary-artery graft on 10-year survival and other cardiac events. N Engl J Med 1986;314:1-6.

4. Otsuka F, Yahagi K, Sakakura K, et al. Why is the mammary artery so special and what protects it from atherosclerosis? Ann Cardiothorac Surg 2013;2:519-26. 
5. Taggart DP. Stents or surgery in coronary artery disease in 2013. Ann Cardiothorac Surg 2013;2:431-4.

6. Cao C, Melfi F, Yan T. Minimally invasive thoracic surgery in the 21st century: rise of the robots? Ann Thorac Surg 2014;98:2272.

7. Cao C, Wolfenden H, Liou K, et al. A meta-analysis of robotic vs. conventional mitral valve surgery. Ann Cardiothorac Surg 2015;4:305-14.

8. Cao C, Virk S, Wolfenden H, et al. Is a Robotic Operation Safe for Mitral Valve Repair? Ann Thorac Surg 2015;100:2416.

9. DerSimonian R, Laird N. Meta-analysis in clinical trials. Control Clin Trials 1986;7:177-88.

10. Yang M, Wu Y, Wang G, et al. Robotic Total Arterial Off-Pump Coronary Artery Bypass Grafting: Seven-Year Single-Center Experience and Long-Term Follow-Up of Graft Patency. Ann Thorac Surg 2015;100:1367-73.

11. Cheng N, Gao C, Yang M, et al. Analysis of the learning curve for beating heart, totally endoscopic, coronary artery bypass grafting. J Thorac Cardiovasc Surg 2014;148:1832-6.

12. Srivastava S, Barrera R, Quismundo S. One hundred sixtyfour consecutive beating heart totally endoscopic coronary artery bypass cases without intraoperative conversion. Ann Thorac Surg 2012;94:1463-8.

13. Dhawan R, Roberts JD, Wroblewski K, et al. Multivessel beating heart robotic myocardial revascularization increases morbidity and mortality. J Thorac Cardiovasc Surg 2012;143:1056-61.

14. Balkhy HH, Wann LS, Krienbring D, et al. Integrating coronary anastomotic connectors and robotics toward a totally endoscopic beating heart approach: review of 120 cases. Ann Thorac Surg 2011;92:821-7.

15. Jegaden O, Wautot F, Sassard T, et al. Is there an optimal minimally invasive technique for left anterior descending coronary artery bypass? J Cardiothorac Surg 2011;6:37.

16. Srivastava S, Gadasalli S, Agusala M, et al. Robotically Assisted Beating Heart Totally Endoscopic Coronary Artery Bypass (TECAB). Is There a Future? Innovations (Phila) 2008;3:52-8.

17. Fleck T, Tschernko E, Hutschala D, et al. Total endoscopic CABG using robotics on beating heart. Heart Surg Forum 2005;8:E266-8.

18. Boyd WD, Kodera K, Stahl KD, et al. Current status and future directions in computer-enhanced video- and robotic-assisted coronary bypass surgery. Semin Thorac Cardiovasc Surg 2002;14:101-9.

19. Zaouter C, Imbault J, Labrousse L, et al. Association of Robotic Totally Endoscopic Coronary Artery Bypass Graft
Surgery Associated With a Preliminary Cardiac Enhanced Recovery After Surgery Program: A Retrospective Analysis. J Cardiothorac Vasc Anesth 2015;29:1489-97.

20. Argenziano M, Katz M, Bonatti J, et al. Results of the prospective multicenter trial of robotically assisted totally endoscopic coronary artery bypass grafting. Ann Thorac Surg 2006;81:1666-74; discussion 1674-5.

21. Daniel WT, Liberman HA, Kilgo P, et al. The impact of clopidogrel therapy on postoperative bleeding after robotic-assisted coronary artery bypass surgery. Eur J Cardiothorac Surg 2014;46:e8-13.

22. Fujita T, Hata H, Shimahara $Y$, et al. Initial experience with internal mammary artery harvesting with the da Vinci Surgical System for minimally invasive direct coronary artery bypass. Surg Today 2014;44:2281-6.

23. Halkos ME, Liberman HA, Devireddy C, et al. Early clinical and angiographic outcomes after robotic-assisted coronary artery bypass surgery. J Thorac Cardiovasc Surg 2014;147:179-85.

24. Leyvi G, Forest SJ, Srinivas VS, et al. Robotic coronary artery bypass grafting decreases 30-day complication rate, length of stay, and acute care facility discharge rate compared with conventional surgery. Innovations (Phila) 2014;9:361-7; discussion 367.

25. Bayramoglu Z, Caynak B, Ezelsoy M, et al. Angiographic evaluation of graft patency in robotic-assisted coronary artery bypass surgery: 8 year follow-up. Int J Med Robot 2014;10:121-7.

26. Hemli JM, Henn LW, Panetta CR, et al. Defining the learning curve for robotic-assisted endoscopic harvesting of the left internal mammary artery. Innovations (Phila) 2013;8:353-8.

27. Liu TJ, Shih MS, Lee WL, et al. Hypoxemia during onelung ventilation for robot-assisted coronary artery bypass graft surgery. Ann Thorac Surg 2013;96:127-32.

28. Daniel WT, Puskas JD, Baio KT, et al. Lessons learned from robotic-assisted coronary artery bypass surgery: risk factors for conversion to median sternotomy. Innovations (Phila) 2012;7:323-7.

29. Poston RS, Tran R, Collins M, et al. Comparison of economic and patient outcomes with minimally invasive versus traditional off-pump coronary artery bypass grafting techniques. Ann Surg 2008;248:638-46.

30. Srivastava S, Gadasalli S, Agusala M, et al. Use of bilateral internal thoracic arteries in $\mathrm{CABG}$ through lateral thoracotomy with robotic assistance in 150 patients. Ann Thorac Surg 2006;81:800-6; discussion 806.

31. Turner WF Jr, Sloan JH. Robotic-assisted coronary 
artery bypass on a beating heart: initial experience and implications for the future. Ann Thorac Surg 2006;82:7904; discussion 794.

32. Subramanian VA, Patel NU, Patel NC, et al. Robotic assisted multivessel minimally invasive direct coronary artery bypass with port-access stabilization and cardiac positioning: paving the way for outpatient coronary surgery? Ann Thorac Surg 2005;79:1590-6; discussion 1590-6.

33. Mariani MA, D'Alfonso A, Codecasa R, et al. Roboticassisted off-pump coronary surgery. Ital Heart J 2002;3:29S-33S.

34. Sabashnikov A, Patil NP, Weymann A, et al. Outcomes after different non-sternotomy approaches to left singlevessel revascularization: a comparative study with up to 10year follow-up. Eur J Cardiothorac Surg 2014;46:e48-55.

35. Kiaii B, McClure RS, Stitt L, et al. Prospective angiographic comparison of direct, endoscopic, and telesurgical approaches to harvesting the internal thoracic artery. Ann Thorac Surg 2006;82:624-8.

36. Bonaros N, Schachner T, Lehr E, et al. Five hundred cases of robotic totally endoscopic coronary artery bypass grafting: predictors of success and safety. Ann Thorac Surg 2013;95:803-12.

37. Kappert U, Tugtekin SM, Cichon R, et al. Robotic totally endoscopic coronary artery bypass: a word of caution implicated by a five-year follow-up. J Thorac Cardiovasc Surg 2008;135:857-62.

38. de Cannière D, Wimmer-Greinecker G, Cichon R, et al. Feasibility, safety, and efficacy of totally endoscopic coronary artery bypass grafting: multicenter European experience. J Thorac Cardiovasc Surg 2007;134:710-6.

39. Mishra YK, Wasir H, Sharma KK, et al. Totally endoscopic coronary artery bypass surgery. Asian Cardiovasc Thorac Ann 2006;14:447-51.

40. Kiani S, Brown AK, Kurian DJ, et al. Risk of renal dysfunction after less invasive multivessel coronary artery bypass grafting. Innovations (Phila) 2012;7:180-6.

41. Caynak B, Sagbas E, Onan B, et al. Robotically enhanced coronary artery bypass grafting: the feasibility and clinical outcome of 196 procedures. Int J Med Robot 2009;5:170-7.

42. Cavallaro P, Rhee AJ, Chiang Y, et al. In-hospital mortality and morbidity after robotic coronary artery surgery. J Cardiothorac Vasc Anesth 2015;29:27-31.

43. Casula R, Khoshbin E, Athanasiou T. The midterm outcome and MACE of robotically enhanced grafting of left anterior descending artery with left internal mammary artery. J Cardiothorac Surg 2014;9:19.

44. Vainrub S, Patanwala AE, Cosgrove R, et al. Bleeding outcomes in patients given clopidogrel within 5 days of robotic coronary artery bypass graft procedure. Ann Pharmacother 2014;48:48-53.

45. Yang $M$, Gao CQ, Wu Y, et al. Robotic internal thoracic artery harvesting: the learning curve and graft patency. Chin Med J (Engl) 2013;126:1982-3.

46. Anderson JE, Chang DC, Parsons JK, et al. The first national examination of outcomes and trends in robotic surgery in the United States. J Am Coll Surg 2012;215:107-14; discussion 114-6.

47. Currie ME, Romsa J, Fox SA, et al. Long-term angiographic follow-up of robotic-assisted coronary artery revascularization. Ann Thorac Surg 2012;93:1426-31.

48. Hemli JM, Darla LS, Panetta CR, et al. Does dual antiplatelet therapy affect blood loss and transfusion requirements in robotic-assisted coronary artery surgery? Innovations (Phila) 2012;7:399-402.

49. Folliguet TA, Dibie A, Philippe F, et al. Roboticallyassisted coronary artery bypass grafting. Cardiol Res Pract 2010;2010:175450.

50. Loisance DY, Nakashima K, Kirsch M. Computer-assisted coronary surgery: lessons from an initial experience. Interact Cardiovasc Thorac Surg 2005;4:398-401.

51. Novick RJ, Fox SA, Kiaii BB, et al. Analysis of the learning curve in telerobotic, beating heart coronary artery bypass grafting: a 90 patient experience. Ann Thorac Surg 2003;76:749-53.

52. Damiano RJ Jr, Tabaie HA, Mack MJ, et al. Initial prospective multicenter clinical trial of roboticallyassisted coronary artery bypass grafting. Ann Thorac Surg 2001;72:1263-8; discussion 1268-9.

53. Prasad SM, Ducko CT, Stephenson ER, et al. Prospective clinical trial of robotically assisted endoscopic coronary grafting with 1-year follow-up. Ann Surg 2001;233:725-32.

54. Shahian DM, O'Brien SM, Filardo G, et al. The Society of Thoracic Surgeons 2008 cardiac surgery risk models: part 1--coronary artery bypass grafting surgery. Ann Thorac Surg 2009;88:S2-22.

55. Serruys PW, Morice MC, Kappetein AP, et al. Percutaneous coronary intervention versus coronary-artery bypass grafting for severe coronary artery disease. N Engl J Med 2009;360:961-72.

Cite this article as: Cao C, Indraratna P, Doyle M, Tian DH, Liou K, Munkholm-Larsen S, Uys C, Virk S. A systematic review on robotic coronary artery bypass graft surgery. Ann Cardiothorac Surg 2016;5(6):530-543. doi: 10.21037/acs.2016.11.08 